\title{
Parentesco entre Espécies no Nordeste Indígena: árvores cosmogenealógicas e metáforas vegetais
}

Leandro Durazzo ${ }^{a}$

Resumo: Este texto reflete sobre parentesco a partir de elementos indígenas do Nordeste brasileiro, suas relações pragmáticas e metafóricas com outros estratos do ambiente habitado, onde convivem humanos, mais-que-humanos (os entes encantados) e onde ações cosmopolíticas se realizam. Pela ampliação da categoria antropológica, em que instâncias não-humanas estabelecem relações de significação nos sistemas de parentesco, exploramos dois casos indígenas: os processos de fazer parentes e dar continuidade ao grupo étnico Tremembé (CE), na relação com o ritual do torém e com o mocororó, bebida preparada do caju; e a metaforização étnica e cosmopolítica de cacique Xikão do povo Xukuru do Ororubá (PE), assassinado em 1998 e plantado para que dele nascessem novos guerreiros. No limite, estes casos contribuem para entendermos modos de existência sócio-cosmológicas e interespecíficas, experiências de territorialidades, dando-nos elementos indígenas para pensarmos modos de vida alternativos em um período de crise ambiental profunda.

Palavras-chave: Parentesco, Povos Indígenas do Nordeste, Ambiente, Territorialidade, Antropoceno.

Em tempos de crise ambiental, de alcance global e causas seguramente antropogênicas (Danowski \& Viveiros de Castro 2014; Stengers 2015), têm-se buscado alternativas ao que desponta como um colapso da sociedade moderna hegemônica, de economia global e influência marcadamente ocidental. Essa marca moderna e ocidental

a Doutor em Antropologia Social (UFRN). Membro dos grupos de pesquisa Etapa (UFRN), Opará (UNEB) e Macondo (UFRPE/UAST). Email: leandrodurazzo@ gmail.com. 
encontra-se tão entranhada no entendimento da realidade contemporânea global que, a despeito desta era ser chamada de Antropoceno (o tempo dos impactos geológicos influenciados pelo anthropos, pela humanidade), tem-se dado a ela outros nomes que complementem e especifiquem o Antropoceno.

Como nem toda a humanidade, de todos os tempos e lugares, legou ao planeta uma crise ambiental tão devastadora, propõe-se também chamar nossa era de Plantationoceno e Capitaloceno (Haraway 2016). Por tal expediente, responsabiliza-se a humanidade, mas não em sua totalidade. Antes, localiza-se a crise ambiental, a devastação da saúde planetária e a exploração intensiva de recursos ao processo histórico que, tendo se iniciado na Modernidade europeia, nos últimos séculos foi-se expandindo globalmente, legando a grande parte do planeta um regime capitalista de exploração (dos humanos pelos humanos, mas também do ambiente pelos humanos ${ }^{1}$ ). Plantation e capital, portanto.

Donna Haraway, contudo - e ecoando Anna Tsing (2019), que busca formas de viver nas ruínas do capitalismo ao pensar paisagens multiespécies - aponta que o Antropoceno/Capitaloceno/Plantantionoceno pode ser visto também como o que chama de Chthuluceno (Haraway 2016). Esta seria uma era de possibilidades de emergência, conquanto 'contaminadas' pelas múltiplas espécies que emergem integradamente (cf. Tsing 2019:23), mas, sobretudo, emergência de

"poderes e forças tentaculares de toda a terra e das coisas recolhidas com nomes como Naga, Gaia, Tangaroa (emerge da plenitude aquática de Papa), Terra, Haniyasu-hime, Mulher-Aranha, Pachamama, Oya, Gorgo, Raven, A'akuluujjusi e muitas mais. 'Meu' Chthuluceno, mesmo sobrecarregado com seus problemáticos tentáculos gregos, emaranha-se com uma miríade de temporalidades e espacialidades e uma miríade de entidades em arranjos intra-ativos, incluindo mais-que-humanos, outros-que-não-humanos, desumanos e humano-como-húmus (human-as-humus)" (Haraway 2016:140).

Essa multiplicidade de seres (sumariados por Haraway a partir de entidades mitológicas - cosmológicas - de diferentes tradições) permi- 
te-nos pensar no momento atual do Antropoceno não apenas como crise tendendo à ruína, mas, novamente com Tsing (2019), como possibilidade de entender os escombros do capitalismo como campo fértil, embora 'contaminado', para repensar as relações humanas. E, por relações humanas, queremos dizer suas potencialidades interespecíficas, as relações humanas com o ambiente habitado ( $c f$. Cardoso 2018), as relações sócio-cosmológicas entre humanos e mais-que-humanos (Durazzo 2019) e, como veremos a partir de casos indígenas do Nordeste brasileiro, as possibilidades metafóricas e cosmológicas das relações de parentesco e etnicidade.

A própria Haraway já alertava para o poder das metáforas no que tange às formas de viver - e às formas de vida - de nossa realidade. Diz-nos a autora:

"Eu sou uma compostista, não uma pós-humanista: somos todos compostos, adubo, não pós-humanos. O limite que é o Antropoceno/Capitaloceno significa muitas coisas, incluindo o fato de que a imensa destruição irreversível está realmente ocorrendo, não só para os 11 bilhões ou mais de pessoas que vão estar na terra perto do final do século 21, mas também para uma miríade de outros seres [...] $\bigcirc$ Chthuluceno precisa de pelo menos um slogan [...], eu proponho 'Faça Parentes, Não Bebês!'. Fazer parentes é, talvez, a parte mais difícil e mais urgente do problema [...] Bactérias e fungos são excelentes para nos dar metáforas, mas, metáforas a parte (boa sorte com isso!), nós temos um trabalho de mamífero a fazer com os nossos colaboradores e co-trabalhadores sim-poiéticos, bióticos e abióticos. Precisamos fazer parentes sim-chthonicamente, sim-poieticamente. Quem e o que quer que sejamos, precisamos fazer com - tornar-com, comporcom - os 'terranos' (obrigado por esse termo, Bruno Latour-em-modo anglófono). Nós, pessoas humanas em todos os lugares, devemos abordar as urgências sistêmicas intensas [...]" (Haraway 2016:141, grifos nossos).

Tomando o mote proposto por Haraway ('Faça Parentes, Não Bebês!') como ponto de partida de nossa reflexão enológica, veremos adiante como relações simbólicas, simbióticas e sim-poiéticas entre humanos, não-humanos (vegetais) e mais-que-humanos (encantados) servem aos povos indígenas do Nordeste. Por meio de tais relações, 
esses povos se pensam e se criam enquanto coletividades humanas, mas também cosmológicas, numa dinâmica verdadeiramente cosmopolítica (cf. de la Cadena \& Peña 2014). Ainda com Haraway:

“Meu propósito é fazer com que 'parente' signifique algo diferente, mais do que entidades ligadas por ancestralidade ou genealogia [...] Fazer parentes é fazer pessoas, não necessariamente como indivíduos ou como seres humanos. Na Universidade, fui movida pelos trocadilhos de Shakespeare, kin e kind (parente e gentil em português) - os mais gentis não eram necessariamente parentes de uma mesma família; tornar-se parente e tornar-se gentil (como categoria, cuidado, parente sem laços de nascimento, parentes paralelos, e vários outros ecos) expande a imaginação e pode mudar a história. Marilyn Strathern me ensinou que os 'parentes', em inglês britânico, eram originalmente 'relações lógicas' e só se tornaram 'membros da família' no século 17. Este, definitivamente, está entre os factoides que eu amo. Saia do inglês e os selvagens se multiplicam. Penso que a extensão e a recomposição da palavra 'parente' são permitidas pelo fato de que todos os terráqueos são parentes, no sentido mais profundo, e já passaram da hora de começar a cuidar dos tipos-como-arranjos (não espécies uma por vez). Parentesco é uma palavra que traz em si um arranjo. Todos os seres compartilham de uma 'carne' comum, paralelamente, semioticamente e genealogicamente. Os antepassados mostram-se estranhos muito interessantes; parentes são não familiares (fora do que pensávamos ser a família ou os genes), estranhos, assombrosos, ativos" (Haraway 2016:142, grifos nossos).

Este texto pretende pensar a noção antropológica de parentesco a partir de elementos indígenas do Nordeste brasileiro, mormente suas relações - pragmáticas e metafóricas - com outros estratos do ambiente que habitam. Considerando brevemente o histórico disciplinar da categoria, concordaremos com Marshall Sahlins (2012) a respeito da preeminência cultural do parentesco. Ainda, pensaremos sua variabilidade dependente de contextos locais e históricos, bem como sua capacidade de tensionar limites conceituais para além da organização estritamente social, acionando dimensões ontológicas e rituais diversas. Seguindo indicações de uma concepção ampliada da categoria antropológica, em que instâncias não-humanas também estabelecem relações de significação nos sistemas de parentesco, exploraremos dois 
elementos indígenas distintos, que favorecem duas reflexões também distintas, embora coerentes.

Num primeiro momento, veremos como uma entidade mítico-ritual compõe a cosmologia do povo Tremembé do Ceará, por meio de uma imagem centrada no mocororó, bebida ritual preparada a partir do caju (Messeder 2012). Essa cosmovisão evidenciará como a noção de parentesco entre os Tremembé aponta para uma vinculação humano-vegetal, por um lado, e também para a continuidade espiritual de uma tradição tomada como constante. Num segundo momento, evidenciaremos um processo de transição ontológica comum no Nordeste indígena, mas o faremos através do caso dos Xukuru do Ororubá, de Pernambuco, que tiveram seu cacique assassinado devido à luta pela terra. Após a morte de Xikão Xukuru, reforçou-se entre o povo do Ororubá uma metáfora também vegetal para designar seus vínculos étnicos. Como veremos, é dito que Xikão foi 'plantado' (em lugar de 'enterrado', cf. Palitot 2003) para que dele nascessem novos guerreiros. A continuidade de uma identificação coletiva xukuru, assim, indica que imagens vegetais, em sua relação com os humanos, podem potencializar as perspectivas indígenas sobre parentesco, ampliando a categoria a níveis interespecíficos prenhes de significado étnico e cultural.

\section{Mutualidade do ser, mutualidade do estar}

A ideia de parentesco como categoria analítica consolida-se na disciplina antropológica como resultado de um desenvolvimento especificamente moderno do pensamento intelectual europeu. De acordo com Joan Bestard, em uma perspectiva que muito se afina à de Marshall Sahlins (2012) enunciada acima, "o parentesco põe em perspectiva os símbolos da modernidade - indivíduo e sociedade - da mesma maneira que a modernidade faz com os símbolos do parentesco - natureza e cultura" (1998:14, tradução nossa²). Desse modo, teríamos o parentesco não apenas como um conceito útil para pensar determinadas relações sociais, mas como um verdadeiro complexo 
de inteligibilidade que evidenciaria premissas epistemológicas fundamentalmente modernas.

A distinção indivíduo/sociedade e sua contraparte natureza/cultura, exemplos do que chamamos grandes divisores do pensamento ocidental, estabeleceria assim certos caminhos para o entendimento das relações humanas com seus universos de símbolos, representações e vínculos sociais mais pragmáticos. Ao mesmo tempo que definidor (ou descritor) de relações interpessoais - como no sistema descritivo em que pai conecta certo sujeito a outro sujeito, filho, e assim por diante - o parentesco como termo divisor também estabeleceria o entendimento dos limites entre natureza e cultura (cf. Lévi-Strauss 1976). Entretanto, tal dicotomia ainda se ampara em uma definição moderna de mundo, em que os sujeitos humanos, claramente 'culturais', se distanciariam constantemente das dimensões 'naturais' que os caracterizariam.

Conforme Marilyn Strathern (1992), ao problematizar a ideia de parentesco tendemos a tomar por garantido o lugar das relações familiares e geracionais, sem atentar para os trajetos específicos que as formam - e os processos que essas mesmas relações vêm a desencadear. Se é verdade que a noção de parentesco reforça a linha divisória entre natureza e cultura, também parecerá verdade, segundo Strathern, que tal divisão sublinhará a legitimidade e temporalidade de categorias como 'tradição' e 'modernidade':

"Relações familiares tendem a ser tomadas como representativas de um tipo primordial de vínculo que, de algum modo, existe fora ou além das maquinações técnicas e políticas do mundo, algo que sofre alterações mais do que atua como força de mudança. De fato, é possível que a manutenção dos laços de parentesco seja vista como uma tradição arquetípica, contráría às condições da vida moderna. Quanto mais ampliada for a rede e mais extenso o alcance das relações de parentesco, ou mais enfática a solidariedade da família, tanto mais tradicionais parecerão. Ainda assim, é possível aceitar a conceituação de uma tradicionalidade e compreender também uma força contemporânea. Justamente pela suposição de que o parentesco corresponde a relações primordiais, os fatos fundamentais que ele reforça sempre constituíram o empreendimento cultural que se constrói a partir dele" (Strathern 1992:11, tradução nossa ${ }^{3}$ ). 
O parentesco, assim, não representa apenas os vínculos familiares ou grupais de determinado coletivo humano, mas estabelece a própria imagem de ancestralidade ou tradição que tal coletivo toma como importante. Não seria despropositado recordar os trabalhos sobre sistemas políticos africanos, organizados por Evans-Pritchard e Meyer Fortes em 1940, já que neles aparece muito da discussão sobre linhagens que compuseram por bastante tempo o interesse de nossa disciplina. Seguir linhagens familiares - por vezes clânicas, por vezes totêmicas, a depender dos estudos etnográficos - tem sido um dos expedientes mais recorrentes para que determinados grupos marquem suas posições políticas frente a outros grupos, estabelecendo outro grande divisor no que tange à definição dos laços sociais.

Nos casos totêmicos, que poderíamos chamar cosmológicos pelas correlações entre humanos/não-humanos que tais sistemas sugerem, muito das ideias de parentesco e linhagem ampliam as noções de uma organização social meramente familiar - queremos dizer, meramente focada em uma unidade familiar descritiva (enfoque, aliás, que Lévi -Strauss já criticara em Radcliffe-Brown, cf. Lévi-Strauss 1976). Desse modo, a própria divisão natureza/cultura estaria posta em xeque, já que a ideia de uma linhagem totêmica representaria extrapolações ao que julgamos, modernamente, serem os domínios da natureza (um totem animal, por exemplo) e da cultura (os grupos humanos organizados a partir de tais linhas de força).

Para adensar tais problemáticas, Rob Brightman informa que a própria ideia de totem deriva, etimológica e linguisticamente, de uma palavra proto-algonquina para designar co-residentes - "por meio da palavra Ojibway do.de.m, 'clã patrilinear', 'epônimo do clã”" (cf. Sahlins 2012:19, tradução nossa ${ }^{4}$ ). Assim sendo, o totemismo desempenharia não apenas uma correlação significativa entre grupos (humanos e não-humanos), nem apenas uma coextensão ontológica entre seres (humanos e mais-que-humanos), mas traria consigo também a noção de coabitação, convivialidade - coetaneidade de diferentes estratos ontológicos, poderíamos dizer, que por serem coetâneos e correlativos 
reforçam e reelaboram significados sobre o que é ser parte de tal ou tal grupo humano.

Haverá também relações possíveis entre totemismo, entendido nos termos acima, e xamanismo - ou entre organização social e práticas sócio-rituais, espirituais, como esboçaremos a seguir para os casos indígenas do Nordeste. Sobre tais relações em outro contexto etnográfico, informa-nos Francesco Spagna:

“Totemismo e xamanismo, no subártico canadense, vinculam-se um ao outro. A própria palavra totem, além de se tornar categoria antropológica generalizante, é um termo derivado da língua algonquina que significa 'clã'. Makwa nin'dodem significa: 'Urso é meu clã', no sentido tanto de uma dimensão social - o clã familiar, que pode ser transmitido em linha materna ou paterna, a depender do grupo - quanto de uma dimensão espiritual. A pertença ao clã surge ainda marcada na cerimônia de iniciação xamânica. $\mathrm{O}$ vínculo com o animal não é simplesmente nominal ou 'heráldico', mas envolve a pessoa num exercício constante de empatia - ou de busca intelectual - no confronto com o próprio animal. Ainda mais caso se trate de um totem secreto ou pessoal, recebido em sonho ou durante a busca visionária” (Spagna 2006:42, tradução nossa ${ }^{5}$ ).

Não nos espantará, portanto, a afirmação dos Tremembé do Ceará segundo a qual o já mencionado mocororó integra o plano sóciocosmológico de suas relações étnicas, de parentesco e tradição. Sendo plausível a consideração de Marilyn Strathern sobre a simultaneidade de noções ditas tradicionais e outras ditas contemporâneas, e sendo também coerente a explicitação de Joan Bestard sobre o caráter evidenciador que o parentesco assume frente aos grandes divisores, aqui nos interessa refletir sobre as dimensões cosmológicas que a ideia de parentesco oferece. Como veremos a seguir, entre os povos indígenas do Nordeste, a correlação entre antepassados e seres não-humanos favorece uma continuidade social e mesmo ontológica de categorias nativas poderosas, como tradição.

Seguiremos um pouco mais as pistas dadas por Marshall Sahlins. Segundo o autor, eis o que define um 'sistema de parentesco': "uma diversidade de participações intersubjetivas, o que também significa 
dizer uma rede de mutualidades do ser" (Sahlins 2012:20, tradução nossa ${ }^{6}$. Com isso, o antropólogo aponta para uma longa tradição de debates tanto antropológicos quanto teológicos: a rede de 'mutualidades do ser' expressa certa mística participativa bastante conhecida na história das religiões (cf. Durand 2001; Buber 2001), certa complementaridade ontológica que não se distancia muito do aspecto espiritual do totemismo/xamanismo/pertencimento clânico, como vimos com Francesco Spagna.

Do lado antropológico, temos a lembrança de Maurice Leenhardt - um missionário cristão - chegando à Nova Caledônia e descobrindo, entre os ilhéus, que a boa nova que trazia, a revelação da 'alma', não era novidade (Leenhardt 1947). Para os nativos da ilha, que tradicionalmente se compreendiam enquanto múltiplos partícipes de um mesmo grupo, a novidade era outra: não a alma, mas o corpo (cf. Sahlins 2012:19). Essa corporalidade recém-descoberta delimitava clara e materialmente o lugar dos ilhéus no mundo.

Sahlins ainda recorre a Roger Bastide (2018) para recordar a noção melanésia de dividuo, posteriormente popularizada também através do trabalho de Marilyn Strathern (1988). Porque a 'dividualidade' concorda em muito com o que um velho neocaledoniano dissera a Leenhardt: "Já sabíamos da existência do espírito. Sempre agimos de acordo com o espírito" (apud Sahlins 2012:19, tradução nossa ${ }^{7}$ ). Tendo sempre agido de acordo com o espírito, nos moldes do que o missionário Leenhardt poderia considerar como uma 'alma' cristã temente a Deus (e ao Espírito Santo), os sujeitos nativos da Nova Caledônia não eram apenas sujeitos individuais, atomizados e circunscritos a um dos pólos de indivíduo/sociedade. Antes - e daí a concordância com a 'dividualidade' - existiriam apenas na medida em que se reconhecessem e vinculassem a outros, seus iguais - ainda que diferentes - e através do espírito fossem ao mesmo tempo "exteriores" e "diferentes" de si mesmos (cf. Sahlins 2012:20).

A mutualidade do ser/estar [mutuality of being] surge em nossa reflexão como vínculo ao mesmo tempo ontológico e político. Por isso, 
julgamos importante uma consideração sobre a polissemia da tradução. É sabido que o verbo inglês to be se traduz, em português e outras línguas neolatinas, por ser e estar, a depender do contexto. Com relação a ser, temos uma acepção muito mais carregada de essencialismos, dado o histórico epistemológico de nossa tradição ocidental - desde a famosa asserção de Parmênides, em que o ser é, e não pode não ser (Severi 2014), até a ainda mais famosa definição de Descartes: 'penso, logo existo', ou seja, 'logo sou'. Esse essencialismo filosófico converge para os grandes divisores modernos, já apresentados: ser indivíduo ou ser sociedade; ser natureza ou ser cultura.

Desse modo, a mutualidade do ser parece algo evidente: reconhecer-se enquanto parte de um grupo específico - étnico, por exemplo possibilita a configuração de um ser coletivo, como o da 'dividualidade' melanésia. É certamente uma perspectiva ontológica, ou melhor, ôntica que funda essa identificação com o 'exterior', identificação com o outro que difere e complementa o si-mesmo. Mas há uma dimensão menos evidente, que nos parece também fundamental: a mutualidade do estar, poderíamos dizer.

Senão vejamos: Maurice Leenhardt ouve na Nova Caledônia que os ilhéus sempre agiram de acordo com o espírito ${ }^{8}$. Há aí uma continuidade ôntica explícita, posto que a memória local identifica seu pertencimento étnico a uma ancestralidade tomada por tradição ('sempre agimos de acordo com o espírito', dizia o interlocutor de Leenhardt). Mas há também um elemento de engajamento processual que expande qualquer ontologia, se esta for entendida como uma série de predicados atribuíveis a entidades distintas. Afinal, os ilhéus sempre agiram de acordo com o espírito. Isto quer dizer que, mais que amparados por um sistema estabelecido, estrutural, de relações ou organização social, o interlocutor de Leenhardt identificava seu grupo como sendo composto por sujeitos ativamente engajados na perpetuação - e, certamente, modificação - de seus parâmetros de pertencimento social ('sempre agimos de acordo...').

Tal identificação/complementaridade, dando-se de modo ontogenético (cf. Ingold 2018), permite-nos entender processos de co-criação, 
de constituição recíproca, algo que se atualiza a cada instância - a cada encontro sim-poiético entre seres (Haraway 2016), mesmo que tais seres não possuam uma individualidade essencial, mas se criem à medida que se relacionam. É a essa mutualidade do estar, mutualidade política e ritual, constantemente ativa e criativa (e inventiva, $c f$. Wagner $2018^{9}$ ), que a seguir fazemos referência.

Entre os povos indígenas do Nordeste é bastante comum a consideração de que o pertencimento étnico, a inserção em determinado grupo, depende do trabalho cotidiano, da participação no trabalho (categoria nativa) que compõe o 'regime do índio' (cf. Grünewald 1993; Valle 1993; Nascimento 1994; Sampaio-Silva 1997:64). Compreendese o trabalho como um modo de lidar com as esferas cosmológicas, as práticas rituais e os engajamentos étnicos que constituem o regime, isto é, o complexo modo de vida - e de visão de mundo - que os índios do Nordeste acionam para designar suas realidades (e também suas relações políticas e institucionais, cf. Carvalho 2011).

Ou seja, o regime é um quadro processual de balizas morais e pragmáticas, amparado em elementos ditos tradicionais, que assegura ao índio e à sua coletividade um reconhecimento interétnico, seja frente ao Estado, seja frente à sociedade não-indígena - ou, ainda, frente a outras etnias também indígenas. Nada muito distante da ideia de parentesco explicitada por Sahlins, poderíamos arriscar. Isso porque há diversos modos de estabelecer parentesco. Para além da filiação ou da aliança matrimonial, teríamos "co-residência, comensalidade, as condições materiais de vida extraídas do mesmo território, a amizade etc" (Sahlins 2012:68, tradução nossa ${ }^{10}$ ). Nos casos nordestinos, ainda, práticas como o regime e o trabalho ritual (cf. Cruz 2017:125, n. 34; Durazzo 2019; Veras \& Athias 2020) poderiam compor tais identificações e formas coletivas de organização social, como veremos com os Tremembé.

\section{Mocororó, o poder do espírito}

$\mathrm{Na}$ realidade indígena brasileira, os elementos que conectam noções de parentesco às de etnicidade possuem entrecruzamentos notá- 
veis. Tomemos o modo padrão de referência entre sujeitos indígenas, independentemente de seus pertencimentos étnicos: ao dizer de qualquer outro indígena, um índio poderá utilizar - e normalmente utiliza - o termo parente para especificar a condição de indianidade frente a um Estado e a uma sociedade majoritariamente não-indígenas. $\mathrm{O}$ que faz um índio, por sua vez, não é apenas sua colocação em dado quadro de parentesco, embora isso seja importante. $\mathrm{O}$ que permite a um sujeito ser reconhecido como indígena é, como já apontamos acima, seu pertencimento e engajamento étnico-político, muitas vezes estabelecido pela participação ritual.

Entre os Tremembé do Ceará, habitantes da costa oeste do estado, há um ritual específico em que os índios consomem uma bebida fermentada a partir do suco do caju, conhecida como mocororó ou garrote (Messeder 2012:34). Marcos Messeder mostra como as práticas rituais, lúdicas e eminentemente étnicas servem a um propósito agregador e politicamente orientado, recordando a dimensão geral do toré como registro político-ritual para os índios do Nordeste (cf. Grünewald 2005), e o torém como registro étnico mais específico entre os Tremembé (Valle 1993, 2004). O autor evidencia a importância do ritual como elemento agregador, que transcenderia as pragmáticas intenções iniciais de uma "'elite' política em contato constante com outros grupos indígenas do Nordeste, em meio aos quais a sacralização constituiu sempre uma preocupação central” (Messeder 2012:36).

Há, de fato, uma preocupação daqueles sujeitos engajados na afirmação étnica tremembé de tomar o torém como um elemento diacrítico central, definidor de uma etnicidade contrastiva. Disso dá-nos conta Carlos Guilherme O. do Valle, que esteve na região no início dos anos 1990. Segundo ele:

"Em 1991, a identificação étnica era muito dissimulada. Não havia nenhum isolamento que facilitasse a pesquisa ou a circunscrição de uma unidade social definida. Os Tremembé eram vizinhos de pessoas que não se auto-atribuíam etnicamente como indígenas e que eram classificadas como de fora [...] Para conhecer os Tremembé foi preciso procurar os toremzeiros, os organizadores da dança do torém. 
Apresentado por eles, conheci muito mais gente, pessoas com quem mantinham relações sociais, atadas por um feixe de significações que definem a etnicidade na situação, os que eram da parte ou da indescendência dos indios" (Valle 2004:288, grifos no original).

Assim, percebe-se um cruzamento entre projetos políticos (a afirmação étnica por meio de performances diacríticas, tais quais a dança do torém) e relações de parentesco mantidas ao longo do tempo em determinado território (a indescendência dos indios que viviam, nesse caso, em Almofala/CE). Mas, ainda que o torém seja parte de uma ação específica, conquanto complexa, e corresponda a um processo de afirmação étnica orientada também politicamente, sua dimensão ritual e cosmopolítica permanece sintomática. Por ele, vemos um mecanismo 'fazedor de parentes' (cf. Haraway 2016) que engendra significados contínuos para um grupo que se compreende congregado. Messeder observa:

"Sem pretender idealizar a relação que eles mantêm com o ritual, mostra-se provável que a experiência atualizada corresponda, em certos aspectos, àquela vivida pelos mais velhos. É evidente que a evolução política dos últimos tempos é responsável pelas reelaborações no significado do ritual. Portanto, mesmo nos colocando em guarda contra a idealização que o movimento político edifica, a prática de reunir as pessoas durante o periodo de produção do mocororó para beber e dançar ao som das canções de Torém traz em si uma intenção memorial de caráter político e reenvia a um plano emocional inegável" (Messeder 2012:37, grifos nossos).

Guardemos o vínculo entre ritual do mocororó, a intenção memorial e a atualização de uma prática social identificada - ainda que intencional e politicamente - "àquela vivida pelos mais velhos". Se prosseguirmos na pista de Sahlins sobre o parentesco como algo mobilizado através de pertencimento coletivo, comensalidade, co-residência, entre outros elementos, teremos no mocororó uma imagem que evidencia, para os próprios Tremembé, a continuidade de sua etnicidade. Etnicidade, ademais, ativada não apenas pelo vínculo 'terrano' (cf. Latour 2020) que a bebida do caju proporciona, mas pelo próprio 
processo de seu preparo, que estimula a convivialidade ao longo da preparação e, depois, favorece a comensalidade e a performance ritual conjunta. Afinal, a "reflexividade intensa em torno do passado, do território, da vida 'dos antigos', de seu cotidiano e de dimensões fortemente simbólicas [...] foi responsável por uma recriação dos discursos e das práticas em torno do sentido da história e da ação coletiva particular aos Tremembé” (Messeder 2012:38). E essa 'recriação' decerto nos permite pensar em modos de habitar o presente e, como quereria Haraway, 'fazer parentes' (2016).

Para além da dimensão intergeracional, valorizada por representar uma experiência equivalente àquela 'dos mais velhos', Messeder nos faz saber de uma metáfora de parentesco bastante significativa para esse processo de memória e lógica cultural que seu artigo enfoca. O antropólogo nos rende a seguinte fala do pajé tremembé Luís Caboclo, que delineia um complexo de sentidos e práticas envolvendo diversos elementos de sua tradição: "o Torém é o pai de tudo isto; ai se encontra todo poder espiritual e o mocororó e o cuiambá é [...] o centro espiritual; eles são a força espiritual e a concentração" (cf. Messeder 2012:38, grifos no original).

O especialista ritual continua estabelecendo suas relações com o mocororó e com todo o complexo xamânico tremembé, que envolve não apenas a bebida mas também o torém, além de outras relações cosmológicas. Diz claramente, por exemplo, ser esta uma "tradição dos antigo", pois "o próprio mocororó ele é um, ele é sagrado de uma maneira que ninguém, ninguém avalia [...] ele é da própria natureza [...] tem poder, ele tem um poder de força, um poder de espírito, uma força espiritual" (apud Messeder 2012:38).

Se considerarmos o poder espiritual que o complexo ritual do torém oferece aos Tremembé e observarmos a escolha terminológica do pajé - para quem o torém é pai - poderemos arriscar uma comparação, se bem que contrastiva, com a dividualidade melanésia, já que nela também compreendemos a organização social, ôntica e política, a partir de uma complementaridade exterior (em que o outro é com- 
plemento, como visto acima). No caso tremembé em tela, é a tradição dos antigos que vincula o povo a uma identidade étnica, e é o engajamento no ritual, no regime do indio, que estabelece a organização social e de inteligibilidade coletiva.

Há uma clara dimensão sagrada no mocororó, que o próprio pajé assinala, e por conta de tal dimensão o antropólogo chega mesmo a utilizar a noção de enteógeno (Messeder 2012:39), isto é, um veículo da divindade através do qual o acesso a distintos estratos de realidade se torna possível. Mas o mocororó aparece não somente como veículo, mas como a própria divindade; não apenas como conector entre índios contemporâneos e seus antepassados, mas como o próprio antepassado. O pajé Luís Caboclo afirma: "porque nossos ancentrais deixaram e os nossos ancentrais com certeza foi o próprio, é o próprio mocororó (quer dizer?) que ele existiu do começo da história e ainda hoje ele existe sem diferença, o mocororó num tem nenhuma diferença pro mocororó antigo" (cf. Messeder 2012:39).

A organização social e cosmológica que o parentesco tremembé parece sugerir - através do torém como 'pai de tudo', mas também da feitura e consumo do mocororó como comensalidade fazedora de parentesco (Sahlins 2012) - coloca-nos a questão, novamente, de uma noção de parentesco antropologicamente ampliada. Não haveria, de fato, um sistema social específico, estruturalmente delineável, destacável das inúmeras dimensões da vida social dos grupos humanos, ao qual pudéssemos dar o título inequívoco de 'parentesco' (Schneider 1972). Pelo contrário, ritualidade, etnicidade, ancestralidade e organização politicamente orientada de uma memória coletiva, por exemplo, se imbricam com termos e ideias de parentesco, atualizando e mesmo revitalizando conceitos - e práticas sociais - outrora vistos como estanques, mesmo para a antropologia.

Essas metáforas vegetais do parentesco e da etnicidade, então, oferecem ainda uma consideração cosmopolítica bastante preciosa. Se lembrarmos dos diversos modos de parentesco, predação e domesticação entre os Jivaro (da Amazônia peruana e equatoriana, cf. Taylor 
2000), recordaremos também como tais economias se encontram interligadas, seja na prática cotidiana do casamento, da caça e da domesticação, seja em seus correlatos linguísticos e epistemológicos, através dos quais eles produzem inteligibilidade sobre seu mundo. Recordaremos também que, entre esse povo, o domínio técnico da produção agrícola e horticultora pertence exclusivamente às mulheres, por uma metáfora produtiva bastante peculiar: se na caça, no casamento e na predação a lógica econômica é a da captura e do amansamento do outro, do diferente, na produção vegetal a metáfora é basicamente oposta. Nesta, o cuidado da terra e das culturas vegetais não se dá pelo amansamento, captura ou predação do outro, mas pela reprodução idêntica do si-mesmo, pela continuidade de um elemento sempre existente.

O pajé do povo Tremembé menciona que o mocororó "ainda hoje ele existe sem diferença". Naturalmente, não pretendemos equalizar as perspectivas cosmológicas de tradição e continuidade entre os Tremembé e os Jivaro, mas certo elemento cíclico presente nessas metáforas parece bastante sintomático. Tal elemento é aquele que, fazendo uso da terra e das metáforas vegetais para especificar a continuidade de determinada ancestralidade (e parentalidade), encontra-se incorporado nas imagens da semente, das plantas e dos frutos - e de seus subprodutos sagrados, como o mocororó. Com isso, diferentes complexos culturais e rituais são trazidos à luz, consideravelmente mais amplos que uma árvore genealógica simplesmente descritiva. Seus galhos, ramas novas e troncos velhos, como veremos a seguir, cumprem uma função política fundamental para a existência indígena no Nordeste, dispondo metáforas vegetais como campo para o entendimento étnico.

\section{Plantar o cacique para que dele nasçam novos guerreiros}

A fim de compreender seus efeitos performativos (Leach 1966; Austin 1974; Bauman 2004; Tambiah 2017) e 'fazedores de parentes' (Haraway 2012), podemos pensar as metáforas como uma correlação 
tentativa entre termos assimétricos (Black 2018). Assim, diferentemente de uma analogia - em que dois sistemas diferentes, mas logicamente equivalentes, podem ser esquematicamente intercambiados - ou de uma comparação - em que os termos e sistemas apresentam semelhanças mais diretas -, a metáfora oferece ao enunciador uma imagem conhecida para a qual traduzir um conteúdo vago, não completamente entendido. Desse modo, fala-se metaforicamente sobre determinado elemento que escapa às definições mais racionalizadas e/ou classificadoras.

Manuela Carneiro da Cunha já apontara certa correspondência a tal ideia ao falar do xamanismo ameríndio como processo de tradução. Em Pontos de vista sobre a floresta amazônica: xamanismo e tradução, ela nos informa que o especialista ritual, em suas viagens aos outros mundos, "observa sob todos os ângulos, examina minuciosamente e abstém-se cuidadosamente de nomear o que vê. Donde a suspensão da linguagem ordinária, substituída por essas 'palavras torcidas'” (Cunha 1998:13). Examinar minuciosamente e se abster - cuidadosamente - de nomear o que se vê, justamente porque aquilo que se vê - e que se tenta nomear - foge a delineamentos claros e distintos.

Também Pedro Cesarino, de certo modo convergindo com nossas reflexões, trabalha as fórmulas poéticas marubo vendo nelas "o caráter necessário do emprego metafórico da linguagem no xamanismo, uma vez que ele oferece ao xamã o conhecimento sobre o surgimento (wenia) ou a formação (shovia) de todos os entes do cosmos" (Cesarino 2008:2, grifos no original). Metáfora, portanto, chega-nos aqui como condição de aproximação criativa, não como predefinição de categorias ou entidades reificadas. Afinal, tratar-se-iam do 'surgimento' e da 'formação' de todos os entes do cosmos, algo talvez próximo da ação de acordo com o espírito [ancestral/de continuidade étnica] que vimos com Leenhardt (1947).

O caráter fundamental da metáfora, portanto, que já vimos ser verdadeiro para os Tremembé (para quem o torém, com seu mocororó, 
é pai), é também fundamental em outros contextos etnográficos. Porque é através da metaforização de relações sociais, sócio-cosmológicas, intrincadas e muitas vezes indistintas - como o próprio parentesco - que os povos do Nordeste nos dizem de seus mundos e modos de existência. E, assim como pudemos observar no caso tremembé, também entre os Xukuru de Pernambuco as metáforas que interconectam parentesco e vegetalidade se fazem presentes e enraizadas.

Desse modo, chegamos à imagem do cacique Xikão Xukuru, assassinado em 1998 devido a um conflito fundiário acirrado, anterior à demarcação e homologação da Terra Indígena Xukuru pela Funai, ocorrida em 2001 (Palitot 2003; Neves 2005; Santos 2009). O que aqui nos interessa diretamente é pensar os procedimentos funerários levados a cabo após a morte do cacique, como já sumariado acima. Em tais procedimentos, novamente encontramos a linguagem étnica, política e mantenedora de uma memória ancestral, como no caso tremembé, ser investida de um imaginário vegetal, que vincula o povo à terra na qual vivem - e pela qual lutam e morrem.

De acordo com Estevão Palitot, sabemos que a "figura de Xicão passou a ocupar novos patamares após a sua morte. Em relação ao universo político nacional, onde se constitui como líder indígena martirizado, e em relação ao próprio universo Xukuru, onde passa a integrar o mundo sobrenatural dos antepassados" (Palitot 2003:125; também cf. Souza 1992). O autor continua, mencionando a impactante oração que a viúva do cacique, Dona Zenilda Xukuru, fez quando de seu enterro: "Acolhe o teu filho minha Mãe Natureza, acolhe o teu filho!... Ele não vai ser sepultado... ele vai ser plantado, para que dele nasça novos guerreiros!” (cf. Palitot 2003:125).

Temos aqui, de forma explícita, o vínculo de um imaginário xukuru com a continuidade vegetal e com a permanência na - e da - terra. $O$ fato do cacique ser plantado, em certa medida tornado antepassado mítico, mesmo mártir (cf. Rodrigues de Souza 2016), também nos faz pensar na reprodução jivaro: afinal, da árvore plantada nascem frutos e novas sementes de uma mesma espécie. Ou, no caso indígena, fru- 
tos, sementes e guerreiros de um mesmo grupo étnico, que mantém sua organização social como linha de força coletiva, possibilitando modos de organização étnica (Barth 2000) e de uma memória cultural (Messeder 2012).

Esse 'tornar-se antepassado' e a 'plantação' de Xikão talvez já estivessem indicados ao longo de sua trajetória como liderança importante. Se considerarmos, por exemplo, a proximidade já indicada entre regime do indio, seu engajamento político e suas relações com distintos estratos ontológicos no Nordeste, veremos como a própria história de Xikão e de sua esposa, Dona Zenilda, compartilha elementos étnicos e cosmológicos de uma cosmovisão ampliada, amparada na ciência do indio. A noção de uma ciência do índio, variação do regime e do trabalho ritual vistos acima, compõe parte incontornável do vocabulário e das formas indígenas de estar no mundo para diferentes povos do Nordeste (Nascimento 1994; Batista 2005a, 2005b; Durazzo \& Vieira 2016; Durazzo 2019).

A ciência do indio, nesse sentido, seria uma relação sensível, interpessoal e cosmológica com distintos níveis de realidade, dentre os quais os encantados, antepassados, seres das matas e da natureza, entre outros. Dona Zenilda, responsável pela metáfora da plantação de Xikão, como vimos, é tida como uma liderança importante, considerada - pelo povo e por ela própria - como “mãe do povo Xukuru”. Sua relação com o complexo ritual da ciência, do regime do índio, é portanto elemento indispensável para pensarmos a mobilização metafórica de seu trabalho de agricultora indígena, de reprodutora e mantenedora de uma etnicidade coletiva.

Dona Zenilda assim afirma: "O pajé descobriu que eu tinha uma ciência. No momento que Xicão entrou como Cacique, eu desenvolvi essa ciência. É um mistério!” (cf. Almeida 2012:5). Tal afirmação é feita no contexto da narrativa de um evento político bastante sintomático, a saber, uma das retomadas efetivadas pelos Xukuru antes da demarcação da Terra Indígena do Ororubá. Dona Zenilda narra que pedira proteção aos encantados, habitantes de uma esfera onto- 
lógica sagrada e complementar à vida cotidiana. Entrando no que os Xukuru chamam de mata sagrada, Dona Zenilda 'recebeu' um cântico de proteção, graças ao auxílio dos encantados e à sua própria ciência. É válido ressaltar que a ideia xukuru de mata sagrada compõe-se como um sintagma poderoso, fazendo referência ao espaço preferencial para a manifestação da ciência, dos encantados e para a realização dos rituais ${ }^{11}$.

Aliás, é fato conhecido na etnologia do Nordeste que muitos povos, ao dizerem de certa manifestação mediúnica em seus rituais, utilizam a expressão 'enramar', simbolicamente sintomática para nossos interesses ( $c f$. Nascimento 1994, para os Kiriri; Andrade 2008, entre os Tumbalalá; Léo Neto \& Grünewald 2012:57, para os Atikum). A mata sagrada surge quase como a materialização do complexo ritual indígena, corporificando um espaço de múltiplos encontros étnicos e espirituais. A prevalência de seu caráter vegetal, portanto, não poderia passar despercebida, especialmente se lembrarmos que toda essa vasta realidade sócio-ritual envolve, como um de seus pontos mais constantes, o preparo da jurema sagrada, bebida enteógena oriunda das raízes de uma planta nordestina. O que vimos tratando como 'complexos rituais' - como os complexos de relações parentais/vegetais explorados até aqui - deve muito a concepções tais quais 'complexo ritual da jurema' (Nascimento 1994), 'complexo xamânico do toré' (Andrade 2008), 'complexo ritual pankararu' (Carvalho \& Reesink 2018) e 'complexo ritual da ciência' (Durazzo 2019).

É importante observar, ainda, que Dona Zenilda 'desenvolve a ciência' (Almeida 2012:5) quando seu marido assume o cacicado. $O$ reconhecimento da ciência, de sua existência, ocorre a partir de outro ponto também institucionalizado e de autoridade: é apenas depois que o pajé revela a ciência de Dona Zenilda, e apenas depois de recebê -la graças ao cacicado do marido, que sua inserção no complexo ritual xukuru acontece. A 'mãe do povo Xukuru', duplamente autorizada a exercer funções de liderança (pela ciência e pelo pajé), especialidade ritual e mesmo reprodução étnica - como no ato da oração/plantação - torna-se inteligível num quadro de parentesco e especialidade ritual 
intrincado, mesmo inextricável. Como no caso tremembé, sua ação, seu engajamento social, atualiza uma tradição que se constitui por meio da memória dos antepassados, espécie em que Xikão se transforma quando plantado.

\section{Conclusão}

Como vimos, algumas dinâmicas étnicas no Nordeste indígena permitem-nos pensar relações categoriais que a antropologia, desde há muito, toma como temas de estudo. Parentesco, organização social, ritual, relação interespecífica, cosmopolítica, tradição e etnicidade, em vez de termos estanques e noções correspondentes a diferentes domínios da vida social, surgem como intrinsecamente vinculados, com fronteiras inexistentes ou pouco delineáveis em dadas situações etnográficas. Se prosseguirmos nas figuras de linguagem, podemos dizer que tais noções antropológicas e ideias nativas se configuram também como um complexo, a exemplo dos sócio-rituais indicados neste ensaio.

Se o 'pai torém' abre possibilidade para que o ancestral mocororó permaneça sempre o mesmo, dando continuidade e engajamento aos Tremembé do Ceará, o cacique xukuru plantado, dando continuidade aos nascimentos de guerreiros de seu povo, permite a Dona Zenilda, sua viúva, assumir e reafirmar seu papel de 'mãe do povo Xukuru'. O complexo sócio-ritual que se delineia, mais que sistema ou estrutura explicativa, aparece então como campo de possibilidades, articulações e correlações, por vezes analógicas, por vezes metafóricas, das formas de organização social dos mundos indígenas.

Daí a metáfora vegetal potencializar os processos étnicos e políticos de povos indígenas da região. Uma imagem muito comum no Nordeste indígena - e talvez para além dos contextos de indianidade é a dos troncos velhos, das pontas de rama e ainda outras noções vegetais. Segundo João Pacheco de Oliveira:

"Uma metáfora acionada por diferentes grupos [do Nordeste], em variados contextos, conecta as gerações do passado e do presente [...] Os antepassados seriam 'os troncos velhos' e as gerações atuais 'as 
pontas de rama'. Quando as cadeias genealógicas foram perdidas na memória e não há mais vínculos palpáveis com os antigos aldeamentos, as novas aldeias têm de apelar aos 'encantados' para afastar-se da condição de 'mistura' em que foram colocadas. Só assim podem reconstruir para si mesmas a relação com os seus antepassados (o seu 'tronco velho'), podendo vir a redescobrir-se como 'pontas de rama'" (Pacheco de Oliveira 1999:29).

Por serem metáforas, tais imagens oferecem uma tradução inteligível - as partes das plantas que se reproduzem - a um complexo sócio-ritual extremamente vário, e por isso mesmo extremamente indefinível. Como vimos, tal complexo faz convergirem categorias que, analiticamente, chamaríamos ora de parentesco, ora de cosmologia, ora de organização social etc. $\mathrm{O}$ potencial metafórico das imagens vegetais, neste caso, explicita material e imageticamente certos limites que as categorias distintas - parentesco ou cosmologia, por exemplo - carregam consigo.

Oferecendo uma tradução clara a uma ideia difusa e imprecisa - e, mais, a uma realidade constantemente dinamizada pelas necessidades de organização política, de engajamento em demandas por direitos sociais, no confronto com a sociedade e o Estado não-indígenas a metáfora parental/vegetal colabora para a construção de mundos organizacionais inteligíveis a seus atores. Mundos inteligíveis e sumamente conectados ao território e às experiências históricas de territorialidade que diferentes povos elaboram ao longo do tempo (Vieira et al 2015). Territorialidades que há muito tempo apresentam a vida em um ambiente mutável, mas não desconhecido para seus habitantes. Indígena, afinal, é termo que designa justamente aqueles que habitam a terra, que pertencem ao lugar por onde transitam. Terranos desde antes do que hoje se chama Antropoceno. 


\section{Notas:}

1 Exploração e devastação ambiental que, devido a processos predatórios como o desmatamento levado a cabo por posseiros e outros 'produtores' não-indígenas, têm 'afastado [dos espaços de habitação e socialidade indígenas] o encanto e os Encantados' (cf. Veras \& Athias 2020, para o povo Pankararu de Pernambuco).

2 No original: "el parentesco pone en perspectiva los símbolos de la modernidad -individuo y sociedad-, de la misma manera que la modernidad lo hace con los símbolos del parentesco -naturaleza y cultura."

3 No original: "Family relationships are conventionally taken as embodying primordial ties that somehow exist outside or beyond the technological and political machinations of the world, that suffer change rather than act as a force for change. Indeed, the enduring ties of kinship may be regarded as archetypically traditional in antithesis to the conditions of modern life. The wider the network and the more extensive the reach of kin relations or the more emphatic the solidarity of the family, the more traditional they seem. It is, however, possible both to accept that conceptualisation of tradition and to realise its contemporary force. Precisely because kinship is supposed to be about primordial relations, the fundamental facts it endorses have been intrinsic to the cultural enterprise built up after it."

4 No original: "via the Ojibway do.de.m 'patrilineal clan,' 'clan eponym”.

5 No original: "Totemismo e sciamanismo, nel subartico canadese sono legati a doppio filo. La stessa parola totem, oltre a essere diventata una categoria generalizzante dell'antropologia, è un termine derivato dalla lingua algonchina che significa 'clan'. Makwa nin'dodem significa: 'Orso è il mio clan', intendendo sia una dimensione sociale - il clan familiare, che poteva essere trasmesso in linea materna o paterna, a seconda dei gruppi - sia una dimensione spirituale. L'appartenenza al clan viene tuttora rimarcata nelle cerimonie di iniziazione sciamanica. Il legame con l'animale non è mai semplicemente nominale o 'araldico'. Impegna la persona in un esercizio costante di empatia - o di ricerca intellettuale - nei confronti del proprio animale. A maggior ragione se si tratta di un totem segreto e personale, ricevuto in sogno o durante la ricerca di Visione."

6 No original: "a manifold of intersubjective participations, which is also to say, a network of mutualities of being."

7 No original: "We already knew the spirit existed. We have always acted in accord with the spirit."

8 Sobre a tradução de spirit, que o próprio Sahlins indica em seu texto como derivada do francês esprit, não desejamos nos alongar. Entretanto, seria interessante jogar com as possibilidades tradutórias que conferem a esprit não apenas a acepção de spirit, isto é, espirito, mas também aquela de mente, faculdades mentais ou mesmo ânimo (Esprit... s/d).

9 Entenda-se: "invenção é a diferença entre ela própria e a realidade; realidade é a semelhança entre as duas. Como a invenção ou a imitação são o meio da realidade (sua realização), a única realidade que existe é a própria invenção" (Wagner 2018:16, tradução nossa). No original: "invention is the difference between itself 
and reality; reality is the similarity between the two. Just as invention or imitation is the means of reality (realization), so the only reality is that of invention itself".

10 No original: "co-residence, commensality, living off the same land, friendship, etc."

11 Para a centralidade cosmológica e ambiental da mata (ou do mato) nas práticas rituais indígenas do Nordeste, que antecede inclusive o período colonial, ver Nascimento 1994; Pompa 2003; Cardoso 2018; Durazzo 2019.

\section{Referências:}

ALMEIDA, A. et al (ed.). 2012. Nova Cartografia Social dos Povos Tradicionais do Brasil: Xukuru do Ororubá - PE. Manaus: UEA Edições.

ANDRADE, Ugo. 2008. Memória e diferença: os Tumbalalá e as redes de trocas no submédio São Francisco. São Paulo: Humanitas.

AUSTIN, John. 1965. How to do things with words. New York: New York Press.

BARTH, Fredrik. 2000. "Os grupos étnicos e suas fronteiras". In BARTH, Fredrik: O Guru, o Iniciador e Outras Variações Antropológicas, pp. 25-68. Rio de Janeiro: Contracapa Livraria.

BASTIDE, Roger. 2018. "O princípio de individuação (contribuição a uma filosofia africana)". Cadernos de Campo, 27(1):220-232.

BATISTA, Mércia. 2005a. Descobrindo e recebendo heranças: as lideranças truká. Tese de Doutorado. Rio de Janeiro: Universidade Federal do Rio de Janeiro.

. 2005b. "O toré e a ciência Truká". In GRÜNEWALD, R. (ed.): Toré: regime encantado do indio do Nordeste. Recife: Editora Massangana.

BAUMAN, Richard. 2004. A world of other's words: cross-cultural perspectives on intertextuality. Malden: Blackwell Publishing.

BESTARD, Joan. 1998. Parentesco y modernidad. Barcelona: Paidós.

BLACK, Alexis D. 2018. "Wor(l)d-Building : Simulation and Metaphor at the Mars Desert Research Station”. Journal of Linguistic Anthropology, 28(2):137-155.

BUBER, Martin. 2001. Eu e Tu. São Paulo: Centauro.

CARDOSO, Thiago. 2018. Paisagens em transe: ecologia da vida e cosmopolitica Pataxó no Monte Pascoal. Brasília: IEB Mil Folhas.

CARVALHO, Maria Rosário. 2011. "De índios 'misturados' a índios 'regimados”. In CARVALHO, M. R., REESINK, E. \& CAVIGNAC, J. (eds.): Negros no mundo dos indios: imagens, reflexos, alteridades, pp. 337-358. Natal: EDUFRN.

CARVALHO, M. \& REESINK, E. 2018. "Uma etnologia no Nordeste brasileiro: balanço parcial sobre territorialidades e identificacões”. BIB - Revista Brasileira de Informação Bibliográfica em Ciências Sociais, 87(3):71-104.

CESARINO, Pedro. 2008. "A divergência original: tradução xamanística e tradução etnográfica”. Trabalho apresentado na $26^{a}$ Reunião Brasileira de Antropologia, Porto Seguro-BA. 
CRUZ, Felipe. 2017. Quando a terra sair: os indios Tuxá de Rodelas e a barragem de Itaparica: memórias do desterro, memórias da resistência. Dissertação de Mestrado. Brasília: UnB.

CUNHA, Manuela. 1998. "Pontos de vista sobre a floresta amazônica: xamanismo e tradução”. Mana, 4(1):7-22.

DANOWSKI, D. \& VIVEIROS DE CASTRO, E. 2014. Há mundo por vir? Ensaio sobre os medos e os fins. Desterro [Florianópolis]: Cultura e Barbárie/ Instituto Socioambiental.

DE LA CADENA, M. \& PEÑA, J. L. 2014. "Cosmopolítica nos Andes e na Amazônia: como políticas indígenas afetam a política?” Interethnic@ - Revista de Estudos em Relações Interétnicas, 18(1):s/p.

DURAND, Gilbert. 2001. As estruturas antropológicas do imaginário: introdução à arquetipologia geral. São Paulo: Martins Fontes.

DURAZZO, Leandro. 2019. Cosmopolíticas Tuxá: conhecimentos, ritual e educação a partir da autodemarcação de Dzorobabé. Tese de Doutorado. Natal: Universidade Federal do Rio Grande do Norte.

DURAZZO, L. \& VIEIRA, J. G. 2016. "Conhecimentos da mata sagrada, ciência do índio do Nordeste". Trabalho apresentado no $40^{\circ}$ Encontro Anual da ANPOCS, Caxambu-MG.

ESPRIT. 2020. In LAROUSSE, Dictionaire de Français en ligne, s/d. (www. larousse.fr/dictionnaires/francais/esprit; acesso em 10/04/2020).

EVANS-PRITCHARD, E. \& FORTES, M. (ed.). 1980 [1940]. Sistemas Políticos Africanos. Lisboa: Fundação Calouste Gulbenkian.

GRÜNEWALD, Rodrigo. 1993. 'Regime de indio' e faccionalismo: os Atikum da Serra do Umã. Dissertação de Mestrado. Rio de Janeiro: UFRJ. (ed.). 2005. Toré: regime encantado do indio do Nordeste. Recife: Editora Massangana.

HARAWAY, Donna. 2016. “Antropoceno, Capitaloceno, Plantationoceno, Chthuluceno: fazendo parentes”. ClimaCom Cultura Científica, 3(5):139-146.

INGOLD, Tim. 2018. "One world anthropology”. HAU: Journal of Ethnographic Theory, 8(1-2):158-171.

LATOUR, Bruno. 2020. Diante de Gaia: Oito conferências sobre a natureza no Antropoceno. São Paulo/ Rio de Janeiro: UBU/Ateliê de Humanidades Editorial.

LEACH, Edmund. 1966. "Ritualization in man in relation to conceptual and social development”. Philosophical Transactions of the Royal Society, 251:247-526.

LEENHARDT, Maurice. 1947. Do Kamo. La personne et le mythe dans le monde mélanésien. Paris: Gallimard.

LÉO NETO, N. \& GRÜNEWALD, R. 2012. “'Lá no meu reinado eu só como é mel': dinâmica cosmológica entre os índios Atikum, PE”. Tellus, 12(22):49-80.

LÉVI-STRAUSS, Claude. 1976. As estruturas elementares do parentesco. Petrópolis/ São Paulo: Vozes/ EDUSP.

MESSEDER, Marcos. 2012. "Etnicidade e ritual tremembé: construção da memória e lógica cultura”. Revista de Ciências Sociais, 43(2):32-42. 
NASCIMENTO, Marco. 1994. O tronco da jurema. Ritual e etnicidade entre os povos indigenas do Nordeste: o caso Kiriri. Dissertação de Mestrado. Salvador: Universidade Federal da Bahia.

NEVES, Rita de Cássia. 2005. Dramas e performances: o processo de reelaboração étnica Xukuru nos rituais, festas e conflitos. Tese de Doutorado. Florianópolis: UFSC.

PACHECO DE OLIVEIRA, João (ed.). 1999. A viagem da volta: etnicidade, política e reelaboração cultural no Nordeste indígena. Rio de Janeiro: Contra Capa.

PALITOT, Estevão. 2003. Tamain chamou nosso Cacique: a morte do cacique Xicão e a (re)construção da identidade entre os Xukuru do Ororubá. Trabalho de Conclusão de Curso. João Pessoa: Universidade Federal da Paraíba.

POMPA, Cristina. 2003. Religião como tradução: missionários, Tupi e Tapuia no Brasil colonial. Bauru: Edusc.

RODRIGUES DE SOUZA, Edimilson. 2016. "Donos da luta: sacralização de lideranças camponesas e indígenas assassinadas em áreas de conflito fundiário". In FONSECA, C. et al (ed.): Antropologia e direitos humanos, pp. 197-244. Rio de Janeiro: Mórula.

SAHLINS, Marshall. 2012. What kinship is-and is not. Chicago: The University of Chicago Press.

SAMPAIO-SILVA, Orlando. 1997. Tuxá: indios do Nordeste. São Paulo: Annablume.

SANTOS, Hosana O. 2009. Dinâmicas sociais e estratégias territoriais: a organização social Xukuru no processo de Retomada. Dissertação de Mestrado. Recife: Universidade Federal de Pernambuco.

SEVERI, Carlo. 2014. "Transmutating beings: a proposal for an anthropology of thought". Hau: Journal of Ethnographic Theory, 4(2):41-71.

SPAGNA, Francesco. 2006. "Animali spirituali. Tradizioni native del Canada Subartico”. In FERRI L. \& GIANNELLI, L. (eds.): Atti del Convegno Visioni e interpretazioni del Nord. Artico e Subartico, pp. 41-51. Siena: Quaderni del C.I.S.A.I.

SCHNEIDER, David. 1972. "What is kinship all about?". In REINING, Priscilla (ed.): Kinship Studies in the Morgan Centennial Year, pp. 32-63. Washington: Anthropological Society of Washington, .

SOUZA, Vânia. 1992. As Fronteiras do Ser Xukuru: estratégias e conflitos de um grupo indigena no Nordeste. Dissertação de Mestrado. Recife: UFPE.

STENGERS, Isabelle. 2015. No tempo das catástrofes: resistir à barbárie que se aproxima. São Paulo: Cosac Naify.

STRATHERN, Marilyn. 1988. The Gender of the Gift. Problems with Women and Problems with Society in Melanesia. Los Angeles/ London: University of California Press.

STRATHERN, Marilyn. 1992. After nature: English kinship in the late twentieth century. New York: Cambridge University Press.

TAMBIAH, Stanley. 2017 [1973]. "Form and meaning of magical acts: a point of view”. Hau: Journal of Ethnographic Theory, 7(3):451-473. 
TAYLOR, Anne-Christine. 2000. "Le Sexe de la Proie. Répresentation Jivaro du Lien de Parenté”. L'Homme, 154-155:309-334.

TSING, Anna. 2019. Viver nas ruinas: paisagens multiespécies no Antropoceno. Brasília: IEB Mil Folhas.

VALLE, Carlos. 1993. Terra, tradição e etnicidade: um estudo dos Tremembé do Ceará. Dissertação de Mestrado. Rio de Janeiro: Universidade Federal do Rio de Janeiro. . 2004. "Experiência e semântica entre os Tremembé do Ceará". In PACHECO DE OLIVEIRA, J. (ed.): A viagem da volta: etnicidade, politica e reelaboração cultural no Nordeste indigena, pp. 281-341. Rio de Janeiro: Contra Capa.

VERAS, A. \& ATHIAS, R. 2020. Zika, "Chikungunya, Ventos e Encantados entre os Pankararu de Pernambuco". In SCOTT, P., LIRA, L. \& MATOS, S. (eds.): Práticas sociais no Epicentro da Epidemia do Zika, pp. 229-251. Recife: UFPE.

VIEIRA, J., AMOROSO, M. \& VIEGAS, S. 2015. "Apresentação: Dossiê Transformações das Territorialidades Ameríndias nas Terras Baixas (Brasil)”. Revista de Antropologia, 58(1):9-29.

WAGNER, Roy. 2018. The Logic of Invention. Chicago: Hau Books.

\begin{abstract}
This paper reflects on kinship from Indigenous elements of the Brazilian Northeast, their pragmatic and metaphorical relationships with other strata of the inhabited environment where humans, more-than-humans (the enchanted beings) coexist and where cosmopolitical actions take place. By expanding the anthropological category, in which non-human instances establish meaningful relationships in kinship systems, I explore two indigenous cases: the processes of making kin and continuing the Tremembé ethnic group (CE), in relation to the torém ritual and with mocororó, a drink prepared from cashew fruit; and the ethnic and cosmopolitical metaphorization of chief Xikão of the Xukuru people of Ororubá (PE), murdered in 1998 and planted so that new warriors could be born. Ultimately, these cases contribute to understanding socio-cosmological and interspecific modes of existence, experiences of territorialities, giving us Indigenous elements to think about alternative ways of life in a period of profound environmental crisis.
\end{abstract}

Keywords: Kinship, Indigenous peoples from Northeast of Brazil, Environment, Territoriality, Anthropocene.

Recebido em abril de 2020.

Aprovado em maio 2021. 